\title{
The Role of Genetic Mutations in Gene MTHFR in Anencephaly
}

\section{Syndrome}

\section{Shahin Asadi*}

Director of the Division of Medical Genetics and Molecular Research, Molecular Medicine Genetics Harvard University, USA

*Corresponding author: Shahin Asadi, Director of the Division of Medical Genetics

\section{Review Article}

Volume 3 Issue 1

Received Date: January 31, 2019

Published Date: February 15, 2019

DOI: $10.23880 /$ jes- 16000117 and Molecular Research, Molecular Medicine Genetics Harvard University, USA, Email: shahin.asadi1985@gmail.com

\section{Abstract}

Anencephaly syndrome is a genetic disorder that prevents normal growth of the brain and skull bones. This condition can break down the tissues of the nervous system. As a result, people with an anencephaly syndrome lose a large portion of the brain called cerebellum and cerebellum. Anencephaly is a complex disease that is probably caused by the interaction of several genetic and environmental factors. The most known gene for this syndrome is the MTHFR gene, which is based on the short arm of chromosome 1 as $1 \mathrm{p} 36.22$.

Keywords: Anencephaly Syndrome; MTHFR Gene; Brain and Skull Disorders

\section{Generalizations of Anencephaly Syndrome}

Anencephaly syndrome is a genetic disorder that prevents normal growth of the brain and skull bones. This condition occurs when a structure called a neural tube is not able to close during the first few weeks of embryo development. The nerve tube is a layer of cell that ultimately reaches the brain and spinal cord. Since the anencephaly is caused by neural tube disorders, it is classified as a neural tube defect [1].

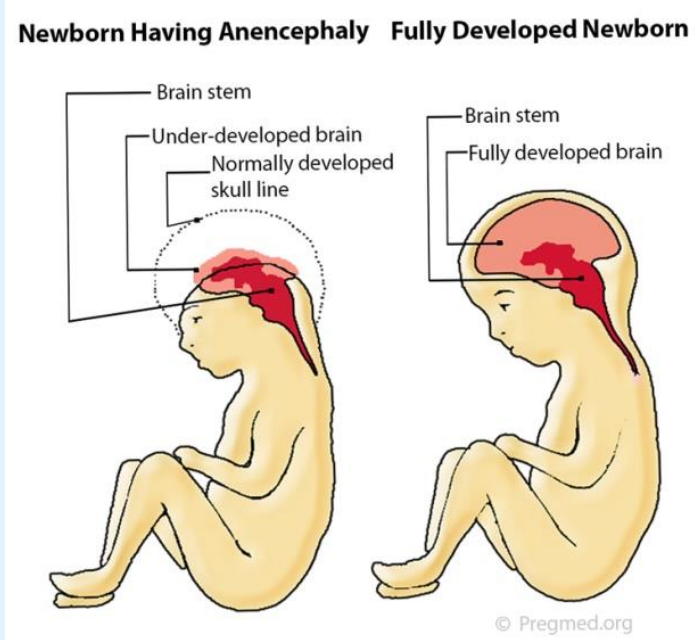

Figure 1: Schematic of normal brain development (right) in the brain with anencephaly (left). 


\section{Journal of Embryology \& Stem Cell Research}

\section{Signs and Clinical Symptoms of Anencephaly Syndrome}

Because the nervous tube in this syndrome cannot be properly closed, the growing brain and spinal cord are exposed to amniotic fluid that surrounds the fetus in the uterus. This condition can break down the tissues of the nervous system. As a result, people with an anencephaly syndrome lose a large portion of the brain called cerebellum and cerebellum. These areas of the brain are essential for thinking, hearing, vision, emotion and coordination of movement. The skull bone is also missing or defective in anecdotes [2].

Because of these disorders, the nervous system is very severe, almost all babies die with anencephaly, before birth, or several hours or days after birth [2].

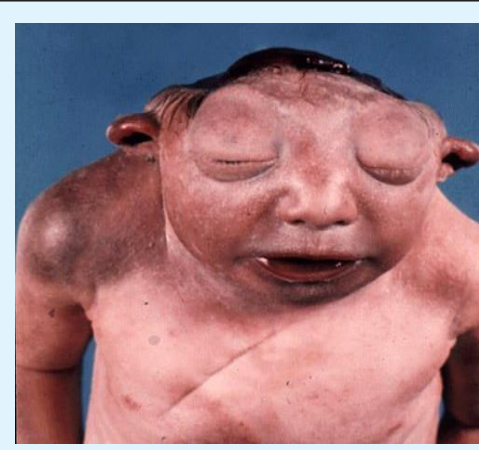

Figure 2: The picture of a newborn with an anencephaly syndrome associated with brain disorders and facial features.

\section{Etiology of Anencephaly Syndrome}

Anencephaly is a complex disease that is probably caused by the interaction of several genetic and environmental factors. Some of these factors have been identified, but many are still unknown. Changes in dozens of genes in people with anencephaly and in their mothers may be at increased risk of developing this type of neural tube defect. The most known gene for this syndrome is the MTHFR gene, which is based on the short arm of chromosome 1 as 1p36.22. This gene provides instructions for protein synthesis that is involved in the processing of vitamin folate (vitamin B9). Deficiency of this vitamin is a dangerous factor for nerve tubal lesions [3].

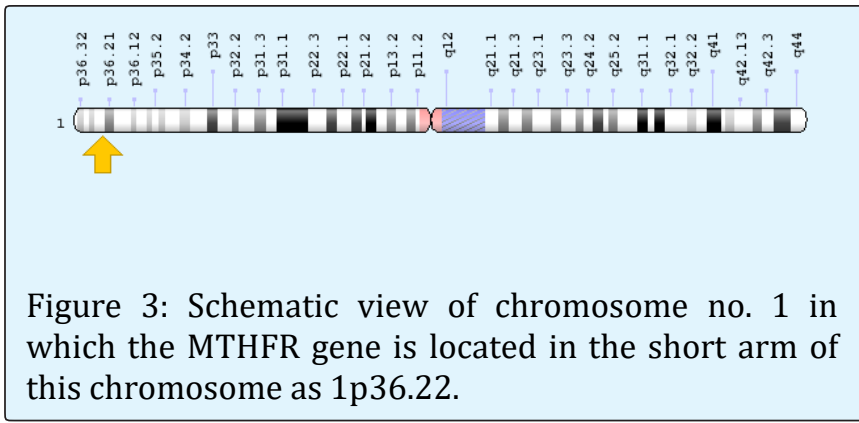

In addition, changes in other genes involved in the processing of vitamin folate and the genes involved in the development of neural tubes have also been studied as potential risk factors for the development of an anencephaly syndrome. However, none of these genes play an important role in creating this condition [4].

Researchers also looked at environmental factors that could be at risk for anencephaly. As noted above, folate deficiency plays an important role. Studies have shown that women who have received supplements containing folic acid (folate) prior to pregnancy and much earlier than their pregnancy are more likely to have a neonate with a neural tube defect, including lessenophilic anencephaly. Other congenital risk factors may include diabetes, obesity, exposure to heat (such as fever or using hot tub or sauna) during early pregnancy, and some antiseizure drugs during pregnancy. However, it is unclear how these factors may affect the risk of anencephaly [5].

Anencephaly syndrome is caused by new gene mutations and no family history. Therefore, no inherited patterns interfere with this syndrome [5].
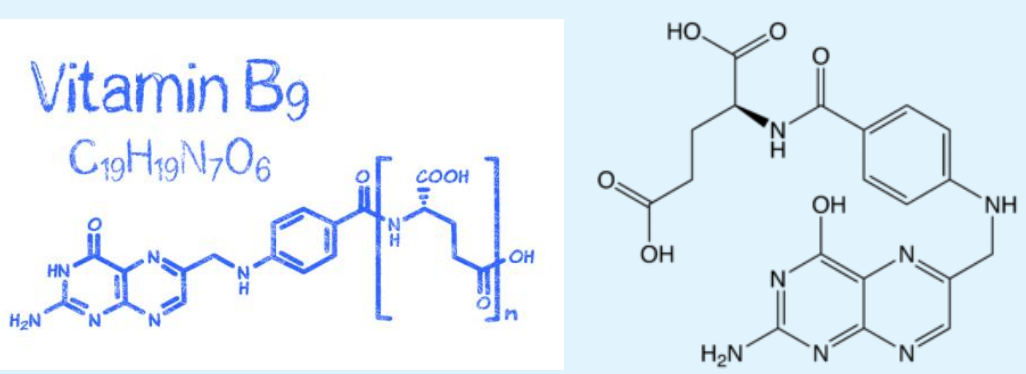

Figure 4: Schematic view of the vitamin B9 structure. 


\section{Journal of Embryology \& Stem Cell Research}

\section{Frequency of Anencephaly Syndrome}

Anencephaly is one of the most common types of neural tube defects that occur in about 1 in 1000 pregnancies. However, many of these pregnancies lead to abortion. Therefore, the prevalence of this syndrome among the newborns is very low. The incidence of anencephaly syndrome in the United States is estimated at about 1 in 10,000 live births [6].

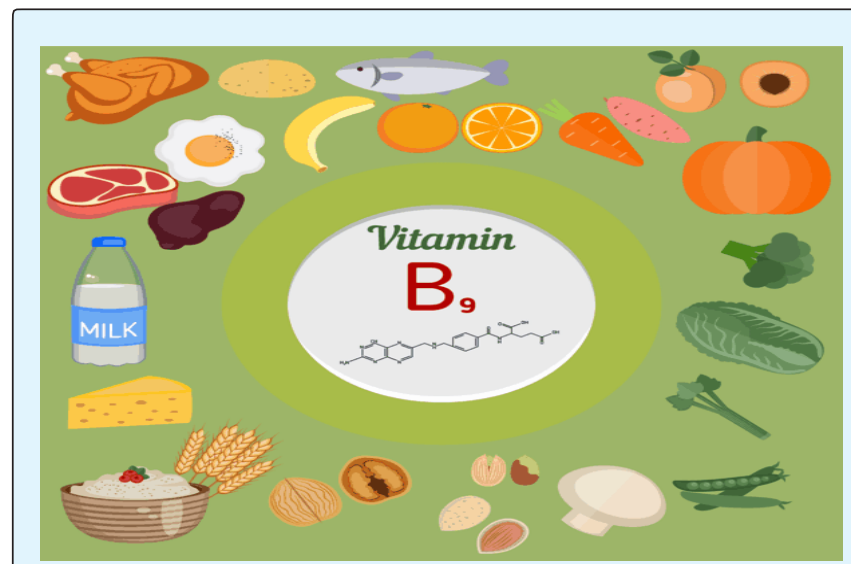

Figure 5: Schematic of foods rich in vitamin B9.

\section{Diagnosis of Anencephaly Syndrome}

Anencephaly syndrome is diagnosed based on the clinical and physical findings of the patients and some pathological examinations. Using radiographic imaging techniques such as ultrasound is also effective in detecting this syndrome. The most accurate method for detecting an anencephaly syndrome is the molecular genetic testing of the MTHFR gene in order to investigate the presence of possible mutations [7].

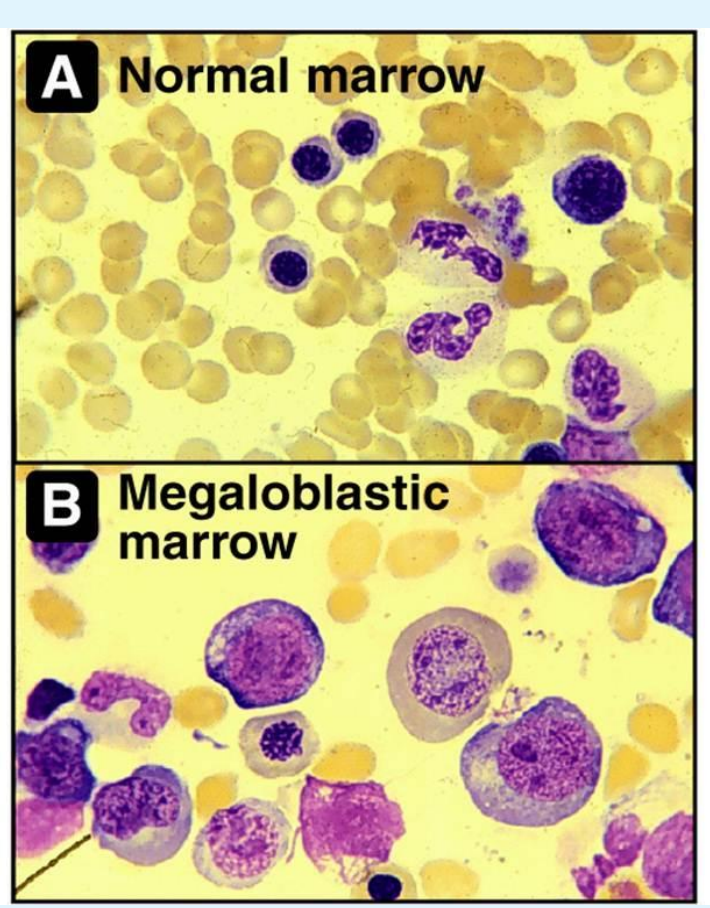

Figure 6: Microscopic Image of normal bone marrow (A) against megaloblastic bone marrow due to vitamin B9 deficiency (B).

\section{Therapeutic Routes in Anencephaly Syndrome}

The strategy of treatment and management of anencephaly syndrome is symptomatic and supportive. Treatment may be done by a team of experts, including neonates, gynecologists, medical specialists and other healthcare professionals. There is no definite treatment for this syndrome, and all patients will die in any case. Genetic counseling is also needed for all parents who want a healthy baby [8-9].
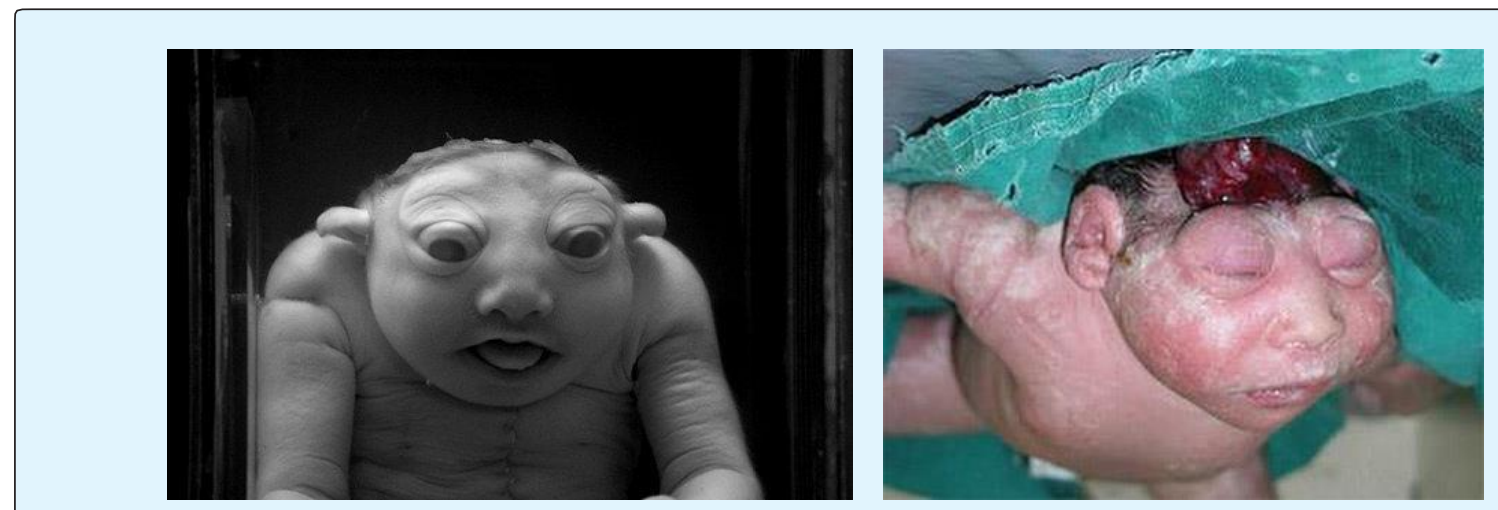

Figure 7: Another view of the newborn with an anencephaly syndrome associated with the related disorder. 


\section{Journal of Embryology \& Stem Cell Research}

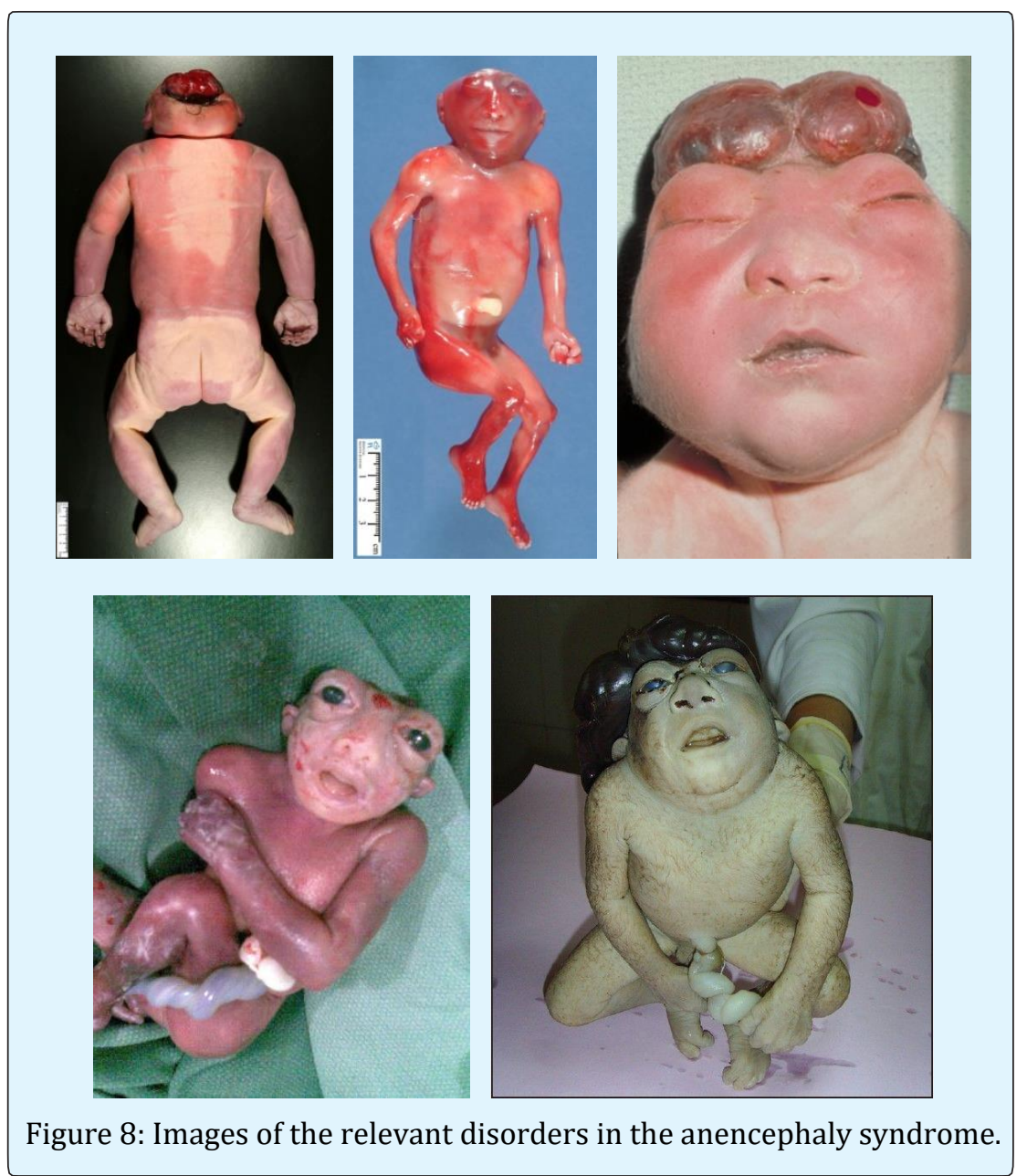

\section{Discussion and Conclusion}

Anencephaly syndrome is a genetic disorder that prevents normal growth of the brain and skull bones. This condition can break down the tissues of the nervous system. As a result, people with an anencephaly syndrome lose a large portion of the brain called cerebellum and cerebellum. Anencephaly is a complex disease that is probably caused by the interaction of several genetic and environmental factors. The most known gene for this syndrome is the MTHFR gene, which is based on the short arm of chromosome 1 as $1 \mathrm{p} 36.22$. There is no definite treatment for this syndrome, and all patients will die in any case.

\section{References}

1. $\mathrm{Au}$ KS, Ashley-Koch A, Northrup H (2010) Epidemiologic and genetic aspects of spina bifida and other neural tube defects. Dev Disabil Res Rev 16(1): 6-15.
2. Bassuk AG, Kibar Z (2009) Genetic basis of neural tube defects. Semin Pediatr Neurol 16(3): 101-110.

3. Botto LD, Moore CA, Khoury MJ, Erickson JD (1999) Neural-tube defects. N Engl J Med 341(20): 15091519.

4. Copp AJ, Greene ND (2010) Genetics and development of neural tube defects. J Pathol 220(2): 217-230.

5. Doudney K, Grinham J, Whittaker J, Lynch SA, Thompson D (2009) Evaluation of folate metabolism gene polymorphisms as risk factors for open and closed neural tube defects. Am J Med Genet A 149A (7): 1585-1589.

6. Greene ND, Stanier P, Copp AJ (2009) Genetics of human neural tube defects. Hum Mol Genet 18(R2): R113-R129. 


\section{Journal of Embryology \& Stem Cell Research}

7. Obeidi N, Russell N, Higgins JR, O'Donoghue K (2010) The natural history of anencephaly. Prenat Diagn 30(4): 357-360.

8. Yan L, Zhao L, Long Y, Zou P, Ji G, et al. (2012) Association of the maternal MTHFR C677T polymorphism with susceptibility to neural tube defects in offsprings: evidence from 25 case-control studies. PLoS One 7(10): e41689.

9. Zhang T, Lou J, Zhong R, Wu J, Zou L, et al. (2013) Genetic variants in the folate pathway and the risk of neural tube defects: a meta-analysis of the published literature. PLoS One 8(4): e59570. 